\title{
A Brief Introduction of Clinical Chinese Pharmacy Education, Training and Practice in China
}

\author{
Zhijian Lin', Yue Li ${ }^{2}$, Bing Zhang1,* \\ ${ }^{1}$ Department of Chinese Pharmacy, School of Chinese Materia Medica, Beijing University of Chinese Medicine, Beijing, CHINA. \\ ${ }^{2}$ Department of Health Policy \& Management, School of Public Health, University of Minnesota, Minneapolis, MN, US.
}

\begin{abstract}
In China, there are two types of pharmacists who work on either Western Medicine (WM) or Traditional Chinese Medicine (TCM). Both are responsible for the provision of pharmaceutical care with safe, effective, efficient and accountable medications for patients. Although Traditional Chinese Pharmacy is not a new subject, it faces a new medical environment and requires a transition. In recent years, Traditional Chinese Pharmacy is emerging as an independent discipline, largely due to global acceptance of TCM. With the development of clinical pharmacy and the increase of patients in need of healthcare services, the role of Chinese pharmacists is requiring an imperative reform. Mechanical tasks such as medication dispension are decreasing in hospital and community pharmacies. This change calls for a new model of traditional Chinese pharmacy education to promote the pharmacists' capacity for advanced direct patient care. Since the late 1990s, some universities and colleges of TCM in China started to offer education and training programs of clinical Chinese pharmacy on various levels. Traditional Chinese Pharmacist education applies training models that closely mirror those of western pharmacists'. Presently, the emphasis of clinical Chinese Pharmacy is beginning to shift to pharmaceutical care practice. With this change, there is an increasing demand for developing clinical skills for clinical Chinese pharmacists, through degree education and non-degree training. So, clinical Chinese pharmacy education requires further development and improvement.
\end{abstract}

Key words: Clinical Chinese Pharmacy, Pharmacist Education and Training, Curricular Framework, Pharmaceutical Care, Traditional Chinese Medicine.

\section{INTRODUCTION}

Traditional Chinese Medicine (TCM), Western Medicine (WM) and the Integration of Traditional and Western medicine are the three kinds of medicine in China. ${ }^{1,2}$ Most WM hospitals have established TCM departments and private health institutions also provide TCM services. ${ }^{3}$ Over the past several decades, TCM has gained ever-increasing international popularity. Nevertheless, the wide use of Chinese herbal medicines may increase the risk of drug-herb interactions and other adverse drug reactions, particularly due to the limitation of pharmaceutical care in TCM practices. ${ }^{4,5}$ Due to these circumstances, an increase in clinical pharmaceutical care is required. ${ }^{6}$
Clinical Chinese pharmacists play an important role in pharmaceutical services and their duties shall include providing recommendations for Chinese herbal medication, offering patient education, engaging in health-promotion activities, analyzing prescriptions, optimizing rational drug use, monitoring therapeutic drug usage and evaluating the safety and costeffectiveness of medication to improve patients' quality of life. ${ }^{7,8}$ This new emphasis on clinical services calls for a reform in Chinese pharmaceutical education. It is urgent to establish an educational program of clinical Chinese pharmacy (CCP). In 2002, The Ministry of Health and the State Administration of Traditional
Submission Date: 31-01-2020; Revision Date: 21-09-2020; Accepted Date: 18-12-2020

DOI: 10.5530/ijper.55.1.6 Correspondence: Prof. Bing Zhang

Beijing University of Chinese Medicine School of Chinese Materia Medica, Chaoyang, Beijing-100029, CHINA. Phone: +86 13488763083

E-mail: zhangb@bucm. edu.cn

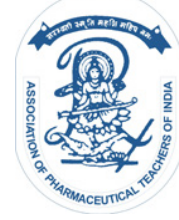

www.ijper.org 
Chinese Medicine issued the Provisional Regulations on Pharmaceutical Administration for Medical Institutions, to satisfy the increasing demand for enhanced healthcare services. These policies and regulations recommended that clinical pharmacists should take part in the diagnosis and treatment of diseases, provide pharmaceutical care and improve the quality of medical care. The steady growth in TCM services has encouraged many colleges to offer CCP education programs in China.

In the past, the routine work of traditional Chinese pharmacists encompassed stocking and dispensing medications, pharmaceutical manufacturing and new drug research and development. ${ }^{9}$ Then, medical resources gradually become abundant under the rapid development of economy and patients have higher expectations for the quality of healthcare services. ${ }^{10}$ Traditional Chinese pharmacists are becoming professional health care providers, who are directly integrated into multi-disciplinary medical teams. Clinical knowledge and skills have become an urgent requirement for traditional Chinese pharmacists. Unfortunately, due to the current curricular system, clinical Chinese pharmacists are lack of clinical experiences. ${ }^{11}$ So, the education and training models of traditional Chinese pharmacy need to be changed to meet this shift and the increasing demand for highquality medical care.

\section{EDUCATIONAL PROGRAM DESCRIPTION}

Prior to the 1950s, Chinese pharmacists were trained in a traditional apprentice system that was prevalent for thousands of years. Modern higher education of traditional Chinese pharmacy in China started in the mid-1950s. ${ }^{12}$ The earliest higher education of TCM began in the Nanjing College of Traditional Chinese Medicine, which had evolved from the Jiangsu Advanced School of Chinese Medicine established in 1954. Four universities (Beijing University of Chinese Medicine, Chengdu University of Traditional Chinese Medicine, Shanghai University of Traditional Chinese Medicine and Guangzhou University of Chinese Medicine) were established during this period of time. They started to provide higher education programs of TCM in 1956 and traditional Chinese pharmacy programs in 1958. Today, there are 45 universities/colleges and 215 research institutions that provide TCM degrees throughout mainland China. ${ }^{13}$ Universities and research institutions of TCM usually offer programs in Chinese medicine, Chinese pharmacy, Acupuncture, Moxibustion, Tuina, Nursing and other TCM-related programs. There are also several vocational schools providing career education or technical training of TCM. According to the academic discipline and degree system in China, the academic disciplines are classified into the first or the second level. ${ }^{14,15}$ First level disciplines are similar to majors in the United States, while the second level disciplines are the equivalent of sub-majors or the branches of majors. The State Council Committee on Academic Degrees of the Ministry of Education has been offering academic degrees in 81 first level disciplines and hundreds of second level disciplines since $1997 .{ }^{16}$ Chinese pharmacy as a first level discipline was established in $1958 .{ }^{17}$ CCP as a second level discipline is a new branch under the first level discipline of Chinese pharmacy. The CCP education model is similar to the model for western pharmacy in China. ${ }^{18}$ There are three levels of degrees in CCP: the Bachelor's degree (first level, BS), the Master's degree (second level, MS) and the Doctoral degree (third level, Ph.D.). Students can receive a bachelor's degree as an entry-level pharmacy degree and then they can obtain a master's degree or a doctoral degree in further studies. Therefore, the classical education model of traditional Chinese pharmacy consists of the 4-year bachelor's degree, the 3-year master's degree and the 3 -year doctoral degree.

In the past two decades, due to the increasing demand of pharmaceutical care in clinical settings, clinical pharmacy education was gradually introduced in some universities to provide well-trained pharmacists with clinical knowledge and skills. ${ }^{11}$ Recently, some universities and research institutions have started to offer CCP education at master's level or doctoral level. In 1998, Beijing University of Chinese Medicine (BUCM) started master's and doctoral degree programs in Chinese pharmacy to promote clinical experience and skills. Today, there are more than 20 universities/research institutions providing master's and/or doctoral degree programs of CCP. In 2001, the State Administration of Traditional Chinese Medicine realized that there was a demand for well-trained clinical Chinese pharmacists and thus listed CCP as a national key discipline. From then on, CCP education has been developing rapidly. In the same year, Beijing University of Chinese Medicine offered the first 7-year CCP program with BM-MM degrees. Students in this program are eligible for licensure as both pharmacists and physicians. In recent years, a few universities have provided bachelor's level education of CCP as pilot teaching modes. From 2011, Shanxi University of Chinese Medicine started to offer a 4-year CCP program with a BS degree. In 2013, Beijing University of Chinese Medicine initiated a 4-year CCP program with a BS degree. In 2015, BUCM developed a pilot clinical pharmacy program of 
a 6-year continuous education model to provide clinical Chinese pharmacist education and training, which was called the "Excellent Pharmacists of Chinese Medicine Program". This 6-year program aims to develop highly qualified professionals who have specialized skills in integrated TCM pharmaceutical care. Beijing University of Chinese Medicine is the only university in China that offers such long-term (7-year and 6-year) CCP degree courses. All these programs are oriented toward patient care and they emphasize promoting pharmacy students with well-trained clinical skills. With all these programs in CCP, a more comprehensive pharmacists' education system has been established and is continuing to develop in China. Currently, there are 19 universities/ research institutions offering master's programs of Clinical Chinese pharmacy, 6 universities/research institutions offering master's programs of Hospital pharmacy, 4 offering Ph.D. programs of Clinical Chinese pharmacy and 2 offering bachelor's programs of Clinical Chinese pharmacy. Only Beijing University of Chinese Medicine offers long-term clinical Chinese pharmacy programs. The CCP education programs are listed in Table 1. The data collection in this study was based on a literature search of data from official websites. All these universities/research institutions that offer CCP programs are state-owned.

From 2008 to 2010, there were 30 students per year graduating from the 7-year CCP BM-MM program at Beijing University of Chinese Medicine. Most of these students obtained both the pharmacist and the physician licenses and served as clinical Chinese pharmacists in hospitals. In recent years, more and more students join the CCP programs. After completing their bachelor's programs in CCP or in other related programs in pharmacy, students can obtain their MS or Ph.D. degrees in CCP. There are two ways to obtain a Ph.D. degree in CCP: completing a 5-year Ph.D. program after graduating from a BS program, or completing a 3-year MS program and a further 3-year Ph.D. program. There are about 20 thousand students graduating from Chinese pharmacy programs every year in China, but less than 1000 among them graduate from CCP programs. After

\begin{tabular}{|c|c|c|c|}
\hline Program & $\begin{array}{l}\text { Academic } \\
\text { Years }\end{array}$ & $\begin{array}{l}\text { Degree } \\
\text { Awarded }\end{array}$ & $\begin{array}{c}\text { List of Universities or Research Institutions } \\
\text { (Total number) }\end{array}$ \\
\hline $\begin{array}{l}\text { Clinical Chinese } \\
\text { Pharmacy } \\
\text { Program }\end{array}$ & 3 & MS & $\begin{array}{l}\text { Beijing University of Chinese Medicine; Tianjin University of Traditional Chinese } \\
\text { Medicine; Hebei University of Chinese Medicine; Shanxi Traditional Chinese } \\
\text { Medicine Institute; Shanxi University of Chinese Medicine; Changchun University } \\
\text { of Chinese Medicine; Heilongjiang University of Chinese Medicine; Yangzhou } \\
\text { University; Nanjing University of Chinese Medicine; Fujian University of Traditional } \\
\text { Chinese Medicine; Chengdu University of Traditional Chinese Medicine; Jiangxi } \\
\text { University of Traditional Chinese Medicine; Henan University of Chinese Medicine; } \\
\text { Hubei University of Traditional Chinese Medicine; Hunan University of Chinese } \\
\text { Medicine; Southern Medical University; Guangzhou University of Chinese } \\
\text { Medicine; Yunnan University of Traditional Chinese Medicine; Shaanxi University } \\
\text { of Chinese Medicine } \\
\text { (19) }\end{array}$ \\
\hline $\begin{array}{l}\text { Hospital Pharmacy } \\
\text { under Chinese } \\
\text { Pharmacy Program }\end{array}$ & 3 & MS & $\begin{array}{l}\text { Beijing University of Chinese Medicine; Shandong University of Traditional } \\
\text { Chinese Medicine; Nanjing University of Chinese Medicine; Shanghai University } \\
\text { of Traditional Chinese Medicine; Henan University of Chinese Medicine; Hebei } \\
\text { University of Chinese Medicine } \\
\text { (6) }\end{array}$ \\
\hline $\begin{array}{l}\text { Clinical Chinese } \\
\text { Pharmacy } \\
\text { Program }\end{array}$ & 3 & Ph.D. & $\begin{array}{c}\text { Beijing University of Chinese Medicine; Heilongjiang University of Chinese } \\
\text { Medicine; Henan University of Chinese Medicine; Chengdu University of } \\
\text { Traditional Chinese Medicine } \\
\text { (4) }\end{array}$ \\
\hline $\begin{array}{l}\text { Clinical Chinese } \\
\text { Pharmacy } \\
\text { Program }\end{array}$ & 4 & BS & $\begin{array}{l}\text { Beijing University of Chinese Medicine; Shanxi University of Chinese Medicine } \\
\text { (2) }\end{array}$ \\
\hline $\begin{array}{l}\text { Long-term Clinical } \\
\text { Chinese } \\
\text { Pharmacy Program }\end{array}$ & 6 or 7 & $\begin{array}{l}\text { BS-MS }{ }^{\mathrm{a}} \text { or } \\
\text { BM-MM }^{\mathrm{b}}\end{array}$ & $\begin{array}{l}\text { Beijing University of Chinese Medicine } \\
\text { (1) }\end{array}$ \\
\hline
\end{tabular}

Abbreviations: BS=Bachelor of Science; MS=Master of Science; Ph.D.=Doctor of Philosophy; BM=Bachelor of Medical Sciences; MM=Master of Medical Sciences. a BS-MS program is a sub-major of Chinese pharmacy 6-year program b BM-MM program is a sub-major of Chinese medicine 7-year program 
obtaining these degrees, CCP students will receive further clinical training in both Western Medicine and Traditional Chinese Medicine.

\section{CURRICULA FOR CLINICAL CHINESE PHARMACY PROGRAMS}

Only two universities provide BS degree programs in CCP in China. Undergraduate students in CCP programs need to complete 4 years ( 8 semesters) of full-time education and trainings. As a new program, the CCP program consists of three series of courses based on didactic and experiential education: the Chinese pharmacy courses, the Traditional Chinese Medicine courses and the CCP courses. There are no standardized curricula or accreditation requirements for these programs. In China, most universities and colleges apply the credit system of "15-18 teaching hours=1 credit". Take BUCM for example, its curricular system consists of three categories, which are described in detail as follows:

(1)The Chinese pharmacy courses include basic science (Mathematics 3 credits, Mathematical Statistics 3 credits, Physics 3 credits, Inorganic and Organic Chemistry 5-7 credits and Analytical Chemistry 4 credits), basic Chinese pharmacy (Chinese Herbology 5 credits, Pharmaceutical Botany 5 credits, Pharmaceutical Zoology 2 credits, Identification of Traditional Chinese Medicine 5 credits, Pharmacology 4 credits, Chemistry of Chinese Materia Medica 5 credits, Processing of Chinese Materia Medica 3 credits, Pharmaceutics of Chinese Materia Medica 6 credits, Drug Synthesis and Principles 2 credits, Chinese Patent Medication 2.5 credits and Pharmacy Administration 3 credits) and pharmacy practice lab experiences courses 20 credits.

(2) Traditional Chinese Medicine courses include modern medicine science (Human Anatomy and Physiology 3 credits, Biochemistry 2 credits, Microbiology and Immunology 2 credits, Pathology 3 credits, Pharmacology and Toxicology 4 credits) and Traditional Chinese Medicine (Fundamental Theories of Chinese Medicine 3 credits, Chinese Medicine Diagnostics 1.5 credits, Chinese Materia Medica and Herbal Formula 6 credits, Chinese Medical Classics 2 credits, Common Disease Treatment and Prevention in TCM 3 credits).

(3) CCP courses include clinical pharmacy practice courses (Introduction to Adverse Drug Reaction and Pharmacovigilance of Chinese Materia Medica 2 credits, Therapeutics of Chinese Materia Medica 3 credits, Theory and Practice of Clinical Chinese Medicine 4 credits, Pharmaceutical Care 2 credits, Herbal Dispensary and Health Care Ethics 2 credits).
Graduates with a BS degree in CCP are eligible for applying for pharmacist licensure.

BUCM is the only university that provides a dual degree (BM-MM) program with seven academic years or a BS-MS program with six academic years in CCP. The 7-year program of CCP education is a combination of pharmacy and physician education. Graduates from this program are eligible for applying for both the pharmacist and the physician licenses. The curriculum of these two programs consists of 2 parts: the core courses of CCP (including Adverse Drug Reaction and Pharmacovigilance of Chinese Materia Medica, Therapeutics of Chinese Materia Medica, Theory and Practice of Clinical Chinese Medicine and Pharmaceutical Care) and the courses of Chinese medical sciences (including Chinese Internal Medicine, Surgery of Traditional Chinese Medicine, Gynecology of Traditional Chinese Medicine, Pediatrics of Chinese Medicine and Acupuncture and Moxibustion and Clinical Rotation as intern physicians). In the final two years of this 7-year program, students participate in patient care in hospitals as master's candidates, where both a physician and a clinical pharmacist serve as the preceptors for the students. The academic durations of both the 6-year and the 7-year programs can be divided into two stages. In the first stage, courses are similar to the 4-year bachelor programs in CCP and these didactic or practical courses are completed in 3.5 years. The students then get pharmacy research training in the lab for 6 months in the fourth year. In the second stage, students enroll as master's candidates, where the courses include Advanced Clinical Pharmacy, Pharmacy Informatics, Introduction to Pharmacy Practice, Pharmaceutical Communications, Applied Pharmacy policy, etc. Students then continue clinical learning in a specialized field of pharmacy practice and complete a research project under the supervision of licensed clinical Chinese pharmacists. Additionally, students need to finish a thesis and an oral defense and publish a research paper in an academic journal to the degrees. Graduates with BS-MS degree in a 6-year program of clinical Chinese Pharmacy are eligible for applying for pharmacist licensure. These two types of long-term CCP programs both emphasize the clinical training for CCP students.

The curricula for master's or Ph.D. degree programs in CCP are widely variable among universities. For example, at Beijing University of Chinese Medicine, the curriculum includes Adverse Drug Reaction and Pharmacovigilance of Chinese Materia Medica, Advanced Clinical Pharmacy, Introduction to Pharmacy Practice, which do not exist in the curricula of the other 
universities. Students must identify a clinical problem for their laboratory work as a research module. There also exists the requirement of publishing research papers in peer reviewed public journals. Clinical training and active engagement in academia are not the emphases in many universities.

Compared with the first level discipline of Chinese pharmacy, a standardized curriculum for CCP has not been established. Even though attention has been paid to clinical pharmaceutical services, with the current curricula of all the CCP programs in China, students may be well-trained in basic sciences, but are still not getting enough exposure to clinical practices. As the innovator in CCP education, Beijing University of Chinese Medicine suggested a curricular system for the 6-year long-term program of CCP in $2013 .{ }^{19}$ The framework of the curricular system is listed in Figure 1. After 5 years' teaching practice, BUCM improved the previous curricular system. This curricular system consists of two modules: a foundational knowledge module and a practice and pharmaceutical care module. The foundational knowledge module includes courses in the pharmaceutical sciences in TCM, the theory and

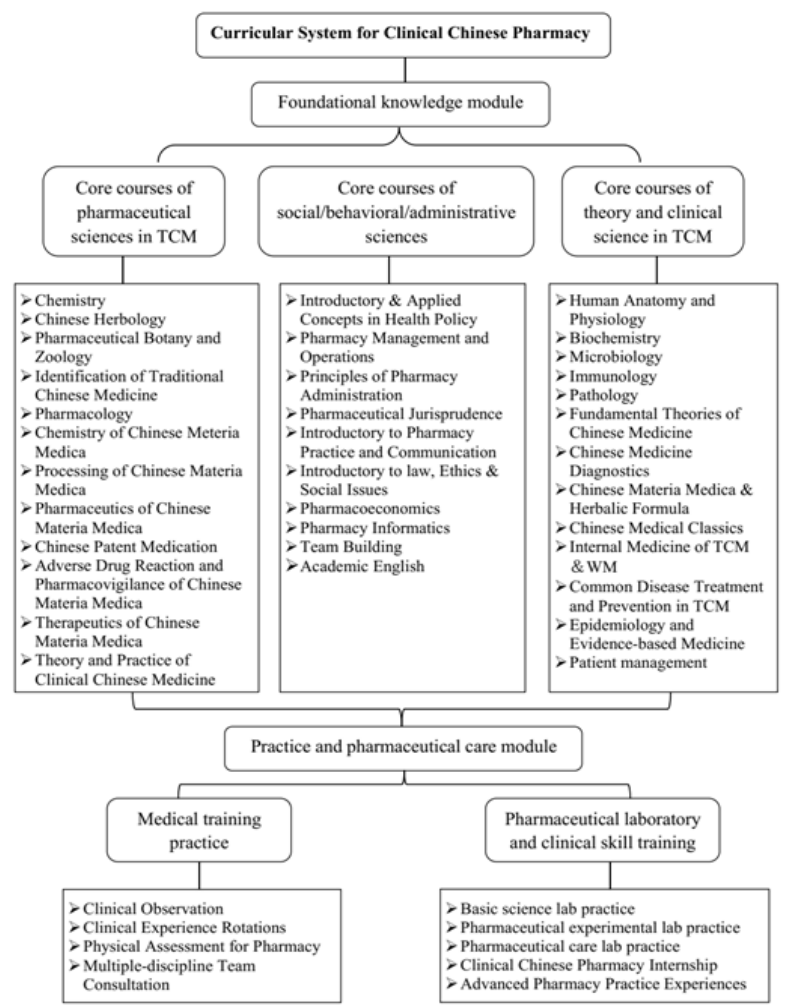

Figure 1: Framework of the curricular system for clinical Chinese pharmacy program.

The framework of the curricular system for clinical Chinese pharmacy program, which includes two main modules: the foundational pharmaceutical knowledge module and the practice and pharmaceutical care module. The emphasis in clinical Chinese pharmacy education is beginning to shift from drug-centered model to patient-centered model. clinical science in TCM and the social/behavioral/ administrative sciences. It aims at helping the students develop, integrate and apply the foundational sciences to evaluate the TCM classical literature and modern scientific literature, design evidence-based therapy, explain drug action, solve therapeutic problems and provide patient-centered pharmaceutical care. The practice and pharmaceutical care module includes courses in medical training and pharmaceutical training.

\section{ADMISSION CRITERIA}

In China, students can join pharmacy programs after high school by two paths. The predominant one is by passing the National College Entrance Examination to pursue higher education in Chinese pharmacy. The candidate's entrance examination score must be above a threshold established by each university. Students are admitted solely on the scores of the standardized entrance examination. The second path is through the special admissions for independent recruitment projects in some universities. Students who have special expertise in TCM can apply for Chinese pharmacy programs and their matriculation depends on both their standardized entrance examination score and their academic achievement in Chinese medicine (counted as extra points added to the candidate's entrance score). For instance, in Beijing University of Chinese Medicine, students can get an extra 20 points added to their entrance score if they have completed courses on foundation of Chinese medicine and have passed the independent recruitment interviews. After graduating from a Bachelor's pharmacy program, students who wish to pursue higher-level degrees in CCP programs must complete an entrance examination for master's or doctoral degree.

Each year, only a few international students enroll in the undergraduate or graduate programs of Chinese pharmaceutical science. However, there haven't been any international students joining the CCP program so far. This may be largely due to the fact that pharmaceutical care is tightly related to the healthcare system, which differs among countries and so do the responsibilities of pharmacists.

\section{STANDARDIZED TRAINING IN CLINICAL CHINESE PHARMACY}

Standardized training in CCP is a type of residency training, similar to the physician residency training or the clinical pharmacist training in China. Before 2017, Clinical Chinese pharmacists had to receive standardized training in the training bases for pharmacists of western 
medicine. In 2016, the China Association of Chinese Medicine (CACM) established an independent training system for pharmacist of Chinese Medicine. ${ }^{20}$ Fortytwo hospitals were certified by CACM as standardized training bases for pharmacists of Chinese medicine. Standardized pharmacist training is a required credential for entry-level pharmacists who want to serve as clinical Chinese pharmacists in hospitals. ${ }^{21}$ There are two kinds of standardized clinical Chinese pharmacist training programs among these hospitals: a 12-month clinical Chinese pharmacist training program in general practice, or a 12-month clinical Chinese pharmacist training program in specialized areas of practice. General clinical Chinese pharmacist training program is the baseline of standardized training, which is designed to enhance general competencies in managing Chinese medication application, as well as supporting optimal medication therapy outcomes for patients with a broad range of disease states or conditions. Specialized clinical Chinese pharmacist training program is based on the competencies achieved in a general clinical Chinese pharmacist training. The specialized training program aims at providing a specific area of CCP practice training, which increases the depth of knowledge related to medication therapy and clinical leadership in the specific area.

\section{PHARMACISTS LICENSURE}

There are two types of pharmacist qualification systems in China, namely the professional qualification system and the specialized qualification system. ${ }^{22}$ In the professional qualification system, only pharmacist candidates who pass the national pharmacist licensing exam can obtain a licensed pharmacist certificate. This exam is overseen by the China Food and Drug Administration and the Ministry of Human Resources and Social Security. It consists of two subtypes: one for pharmacists working on western medicine and the other for those working on Chinese Medicine. After obtaining the qualification certificate, pharmacists can register as licensed pharmacists in the drug administration department of the province, autonomous regions or municipalities directly under the Central Government. A licensed pharmacist is similar to the community pharmacist in the United States. More than $85 \%$ of registered licensed pharmacists work for drug dispensing in wholesale companies or community pharmacies, while the rest work in pharmaceutical manufacturers and other institutions. ${ }^{23}$ Registered licensed pharmacists should be responsible for the quality of drugs and should ensure the safe and effective drug use in pharmacies.According to the specialized pharmacist qualification system, a pharmacist is assigned a specific title, such as chief pharmacist, associate chief pharmacist, pharmacist in-charge, pharmacist, or assistant pharmacist. ${ }^{11}$ They are not required to pass the licensure examination but are required to pass the pharmacist qualification examination overseen by the Ministry of Health. Most of them work in medical institutions, which is similar to the clinical pharmacists in the United States. At present, clinical Chinese pharmacists in medical institutions are the essential members of the clinical care team, who are responsible for ensuring the quality and supply of medications and carrying out "patient-centered" clinical pharmaceutical care. Their routine work includes preparing and dispensing Chinese herbal medications, providing guidance on the use of medications, patient condition assessment, patient therapy plan development, prescription analysis, therapeutic and adverse effects monitoring, patient consultation and reassessment and revision of the medication plan in collaboration with the whole clinical care team. Both of these types of licensed pharmacists should receive continuing education and abide by registration regulations. The continuing education adopts the credit system and mainly focuses on laws and regulations, ethics, Pharmacy, Chinese Medicine and related professional knowledge and skills. Currently, there are more than 425 thousand registered licensed pharmacists and more than 288 thousand specialized pharmacist in medical institutions. ${ }^{24}$ Like western pharmacy graduates, graduates from Chinese pharmacy programs prefer to get a licensed pharmacist certificate and work in the sectors of pharmaceutical manufacture, regulatory affairs, management, quality control and marketing within the pharmaceutical industry. ${ }^{25-27}$ Only a small number of graduates choose to work as clinical Chinese pharmacists in health care institutions. ${ }^{28}$ Due to the increasing clinical demands, as well as the recent policy and regulatory changes issued by the Ministry of Health and the State Administration of Traditional Chinese Medicine, the career preferences of the graduates are also influenced.

\section{EDUCATION QUALITY ASSURANCE}

In China, there has been an improvement in the quality of education during the past 30 years. ${ }^{29-31}$ While there is a professional system for the accreditation of the establishment and the quality assurance of Chinese pharmacy education (CPE), there isn't such a system for CCP education and training. The National Teaching Advisory Committee of Chinese Materia Medica 
under the Ministry of Education has developed many innovative policies of quality assessment for $\mathrm{CPE}$ and training at the national level. ${ }^{32}$ The Ministry of Education conducts education quality evaluation on all schools of Chinese pharmacy every five-years, by reviewing course documents, teaching observation and discussions on teaching quality with students. ${ }^{33}$ This evaluation usually includes three steps: the internal assessment by the school, the external assessment by the National Teaching Advisory Committee of Chinese Materia Medica under the Ministry of Education and a final accreditation decision. Accreditation is an incentive for universities to improve the quality of CPE and training. ${ }^{33}$ Until now, the BS program in CCP is a sub-major and it has not been assessed systematically. Currently, there isn't any recognized international accreditation for traditional Chinese pharmaceutical programs. ${ }^{13}$

\section{CHALLENGES FOR CLINICAL CHINESE PHARMACY EDUCATION}

Traditional Chinese Medicine is widely used throughout the world in modern health systems. The roles of clinical Chinese pharmacists have rapidly evolved and have broadened to direct patient care. Unfortunately, the existing CCP programs cannot adequately prepare the students for these professional demands. ${ }^{18} \mathrm{~A}$ pilot education in CCP has been established in China and has been developing over the past 2 decades. However, compared with the clinical pharmacy of western medicine, the developing pace of CCP is slow. There is still a great shortage of clinical Chinese pharmacists and pharmaceutical services to meet the health care demands. ${ }^{11}$ Each year, there are, altogether, about only 60 graduates from the BS programs in CCP at Beijing University of Chinese Medicine and Shanxi University of Chinese Medicine. The MS and Ph.D. programs in CCP do not have many students either. There are some major challenges to improve CCP education. (1) The basic concepts of clinical pharmacy were introduced to CPE in the mid-1990s and CCP came into being. Because of the rapid development of the pharmaceutical manufacturing industry in China, the CPE is still largely basic science oriented and product-oriented. Chemistry centered courses and laboratory-based courses are still seen as essential in Chinese pharmacy teaching. Although some universities have offered CCP programs, these programs haven't provided systematic clinical training and practical courses yet. Students cannot receive adequate training in clinical pharmaceutical care with the current curricular structure and content. (2) The lack of basic research and evidence-based medicine in TCM is a critical barrier that hinders effective pharmaceutical care services and results in insufficient teaching resources for CCP education. (3) Innovative teaching methodologies of clinical pharmacy education (such as simulated clinical scenario training, case-based learning, simulation patient teaching, peer-learning and student presentations) are often hampered by large class sizes. Furthermore, there is insufficient clinical practice training for the students and the training facilities are not up-to-date. It is urgent to establish pharmaceutical care laboratories and simulation training wards to provide clinical skill training in schools of Chinese pharmacy. (4) Due to time limitation, there isn't enough time to conduct clinical training and practice in the 4-year BS degree programs of CCP. Although there are some schools offering 3-year MS and Ph.D. degree programs in clinical Chinese medicine, most of them focus on clinical pharmacy research instead of clinical training and practice. It is difficult for the students to acquire clinical skills. Furthermore, there aren't any universally accepted frameworks for professional competency or performance standards at the point of graduation or post registration for clinical Chinese pharmacists to ensure uniformity of competency-based clinical skills. (5) Continuing education in CCP, especially on clinical skill training is not enough for pharmacists of Chinese Medicine.

\section{OPPORTUNITIES AND FUTURE DIRECTIONS OF CLINICAL CHINESE PHARMACY EDUCATION}

In China, due to the wide use of Chinese Materia Medica and the shortage of clinical Chinese pharmacists, there is an urgent demand for well-trained clinical Chinese pharmacists. $^{34}$ The Ministry of Health thus issued national guidelines for hospital pharmacies: the National Standards for the Pharmacy Department of Secondary and Tertiary General Hospitals in 2010. This guideline outlines a minimum level of services in hospital pharmacy departments to improve the quality of pharmaceutical care and ensure safe use of medications. This guideline requires that the proportion of clinical pharmacists is at least 30\% in pharmacy departments of tertiary hospitals and at least $20 \%$ in secondary hospitals. In 2011, the Ministry of Health and the State Administration of Traditional Chinese Medicine set a further requirement: the number of clinical pharmacists is at least 5 in a tertiary hospital and 3 in a secondary hospital. In 2017, the Ministry of Health emphasized the importance of clinical pharmacists in a health care team and required them to provide quality, safe and individual pharmaceutical services. These regulations 
indicate that there is an urgent demand for clinical Chinese pharmacists. These are great opportunities to promote reforms in CPE on the development of CCP education and training. The Chinese government and professional associations are encouraging establishments of CCP programs. The Ministry of Health and the State Administration of Traditional Chinese Medicine decide to promote the amelioration of CCP education. Therefore, schools of Chinese pharmacy and universities need to take actions to establish a new model for clinical Chinese pharmacist education and training to overcome the shortage of clinical pharmaceutical care.

These actions include: (1) organization of in-service pharmacy education programs and continuing education projects for existing pharmacists from health centers, hospital pharmacy departments and community pharmacies, who are unable to attend academic programs, to upgrade the knowledge and skills to meet the immediate need. There is also a need to develop bridging programs for existing pharmacists to earn higher degrees in CCP.

(2) improvement of the educational system of schools of pharmacy to increase the number of undergraduate and graduate students in CCP. This can be done through: (1) increasing the enrolment number of students applying to CCP in universities or colleges of pharmacy. (2) Establishing new majors to offer educational programs in CCP. (3) Upgrading teaching facilities in schools of pharmacy, such as establishing pharmaceutical care laboratories, simulation training centers, teaching instruments and pharmacy IT systems. (4) Developing a long-term degree program in CCP that would be similar to the Pharm. D. program in the United States.

(3) Ensuring the quality of CCP education. This can be done by: (1) setting up a national framework of education guidelines for clinical Chinese pharmacy programs and directions. Under these guidelines, schools of Chinese pharmacy could design their own curricula and research programs. Development of new curricula including didactic and practical courses to equip students with the competencies of basic pharmacy knowledge and welltrained clinical skills is necessary. It is also important to develop their skills in communication, pharmacy information use, herb-drug interaction assessment and other CCP activities. (2) Publishing standardized and continuously updated textbooks to make the curricular structure and content of CCP more practical and systematic. (3) Strengthening the cooperation between schools of pharmacy and hospitals. This can be done by recruiting teachers with clinical pharmacy background and experiences. Clinical Chinese pharmacists in affiliated or teaching hospitals should also be included in CCP courses. (4) Performing quality control and accreditation in CCP education programs, especially in clinical knowledge and skill assessment.

\section{CONCLUSION}

In the past two decades, CCP education has been developing rapidly and a number of universities have offered CCP programs at BS, MS and Ph.D. levels in China. However, the core educational idea and the curricular system are still drug-centered rather than patient-centered, with a focus on the basic pharmaceutical sciences. CCP education and CCP practice in China still apply a drug-oriented model, which only partially integrates the concepts of pharmaceutical care. Despite some challenges and barriers to hinder its development, CCP education has a bright future. The recent policy changes on pharmacy administrations issued by the Ministry of Health and the State Administration of Traditional Chinese Medicine will strengthen the development of CCP education and training in the near future in China. To achieve the highest level of pharmacy practice, it is necessary that clinical Chinese pharmacists receive adequate education and training in formal Chinese pharmacy programs (preferably longterm education programs) in universities and during residency. CCP educational system requires an instant reform to keep up with the development and the demand of the Chinese society.

\section{ACKNOWLEDGEMENT}

The authors would like to sincerely thank Professor Qing Wu, the Deputy Dean of the School of Chinese Materia Medica in Beijing University of Chinese Medicine, for providing the reference of teaching plans.

\section{Funding}

This work was supported by the Key Educational Research Projects of Beijing University of Chinese Medicine (Grant No.: XJZX2014; XJZX18002) and partially supported by the Research Projects of "big learning, deep research and implementation" in Chinese Medicine from the State Administration of TCM in China (Grant No.: GY-10).

\section{CONFLICT OF INTEREST}

The authors declare that they have no competing interests. 


\section{ABBREVIATIONS}

WM: Western Medicine; TCM: Traditional Chinese Medicine; CCP: Clinical Chinese Pharmacy; BS: Bachelor of Science; MS: Master of Science; CACM: China Association of Chinese Medicine; CPE: Chinese Pharmacy Education.

\section{REFERENCES}

1. Hesketh T, Zhu WX. Health in China. Traditional Chinese medicine: One country, two systems. BMJ. 1997;315(7100):115-7.

2. Dong J. The Relationship between Traditional Chinese Medicine and Modern Medicine. Evidence-based complementary and alternative medicine. 2013;153148.

3. Wang L, Suo S, Li J, Hu Y, Li P, Wang Y, et al. An investigation Into Traditional Chinese Medicine Hospitals in China: Development Trend and Medical Service Innovation. International Journal of Health Policy and Management. 2016;6(1):19-25.

4. Yuan $\mathrm{H}, \mathrm{Ma} \mathrm{Q}, \mathrm{Ye} \mathrm{L}, \mathrm{Piao} \mathrm{G}$. The Traditional Medicine and Modern Medicine from Natural Products. Molecules. 2016;21(5):559.

5. Zeng ZP, Jiang JG. Analysis of the adverse reactions induced by natural product-derived drugs. British journal of pharmacology. 2010;159(7):1374-91.

6. Zhang F, Xie JM, Zhang YY, Kong LL, Li SC. What Is Important During the Selection of Traditional Chinese Medicine (TCM) in a Health Care Reimbursement or Insurance System?" Critical Issues of Assessment from the Perspective of TCM Practitioners. Value in Health Regional Issues. 2013;2(1):141-6.

7. Chen X, Ung COL, Hu H, Liu X, Zhao J, Hu Y, et al. Community Pharmacists' Perceptions about Pharmaceutical Care of Traditional Medicine Products: A Questionnaire-Based Cross-Sectional Study in Guangzhou, China. Evidence-based Complementary and Alternative Medicine: eCAM. 2016;2016:7801637-.

8. Chaar B, Moles R, Zhai S, Li Y, Hu Y, Penm J. The impact of clinical pharmacy services in China on the quality use of medicines: A systematic review in context of China's current healthcare reform. Health Policy and Planning 2013;29(7):849-72.

9. Zhai $H Q$, Wang YP, Wang YY. Present and future of traditional Chinese medicine clinical pharmacy. Zhongguo Zhong yao za zhi = Zhongguo zhongyao zazhi $=$ China Journal of Chinese Materia Medica. 2013;38(3):45961.

10. Mosadeghrad AM. Factors influencing healthcare service quality. Int $\mathrm{J}$ Health Policy Manag. 2014;3(2):77-89.

11. Yao D, Xi X, Huang $\mathrm{Y}, \mathrm{Hu} \mathrm{H}, \mathrm{Hu} \mathrm{Y}$, Wang $\mathrm{Y}$, et al. A national survey of clinical pharmacy services in county hospitals in China. PloS One. 2017;12(11):e0188354.

12. Fan J, Hua M, Dong H, Sherer R. Reforming Medical Education in China: A Traditional Chinese Medicine Perspective. Med Ed Publish. 2017;6(1).

13. Xue P, Zhan T, Yang G, Farella GM, Robinson N, Weihong YA, et al. Comparison of Chinese medicine higher education programs in China and five Western countries. Journal of Traditional Chinese Medical Sciences. 2015;2(4):227-34.

14. Yang R. Internationalisation, Indigenisation and Educational Research in China. Australian Journal of Education. 2005;49(1):66-88.
15. Wu L, Wang Y, Peng X, Song M, Guo X, Nelson H, et al. Development of a medical academic degree system in China. Medical education online. 2014;19(1):23141.

16. Levin HM, Xu Z. Issues in the Expansion of Higher Education in the People's Republic of China. China Review. 2005;5(1):33-59.

17. Fan J, Hua M, Dong H, Sherer R. Reforming Medical Education in China: A Traditional Chinese Medicine Perspective. Med Ed Publish. 2017;6(1):1-12.

18. Hu M, Yee G, Zhou N, Yang N, Jiang X, Klepser D. Development and current status of clinical pharmacy education in China. American Journal of Pharmaceutical Education. 2014;78(8):157.

19. Zhang B, Wu JR, Lin ZJ. Research on higher educational personnel training of clinical Chinese pharmacy. Int J Trad Chin Med. 2013;35(4):335-7.

20. Sun H, Cao J, Mei Q, Cao G. Urgency and Importance of the Establishment of TCM Clinical Pharmacy Training Base. China Pharmacist. 2016;19(3):510-3.

21. Shi D, Rong CL, Guag G, Wang S, Sun YC. Status and Mode Introduction of the First Batch of Traditional Chinese Medicine Clinical Pharmacists Training. China Licensed Pharmacist. 2018;15(5):78-80.

22. An F, Yu B. The Status and Prospects of the Licensed Pharmacist Qualification System in China. European Journal of Business and Management. 2011;3(5):1-5.

23. Fang Y. Pharmaceutical Policy in China. In Pharmaceutical Policy in Countries with Developing Healthcare Systems Adis, Cham. 2017;169-91.

24. Li Z. Investigate on the Construction and Legislative Suggestions of Licensed Pharmacists in China. Pharmaceutical Administration. 2019;28(6):69.

25. Manasse HR, JrSpeedie MK. Pharmacists, pharmaceuticals and policy issues shaping the work force in pharmacy. American Journal of Pharmaceutical Education. 2007;71(5):82.

26. Cutler TW. The pharmacy profession and health care reform: Opportunities and challenges during the next decade. J Am Pharm Assoc. 2011;51(4):47781.

27. Gums JG. Changing the direction of clinical pharmacy outside the United States: Time to step up. Pharmacotherapy. 2013;33(2):122-5.

28. Chen ZH, Cui YM, Zhou Y, Wang ZN, Ke Y. Peking University Health Science Center Model of Clinical Pharmacy Education and Clinical Pharmacist Services. Chin Med J. 2016;129(23):2890-4.

29. Wang L. Quality assurance in higher education in China: Control, accountability and freedom. Policy and Society. 2017;33(3):253-62.

30. Shuiyun L. External Higher Education Quality Assurance System in China. Chinese Education and Society. 2016;49(1-2):1-6.

31. Liu S. Higher Education Quality Assessment in China: An Impact Study. Higher Education Policy. 2014;28(2):175-95.

32. Yuan Z, Xia X, Yang Y, Zhou X, Yan H. Discussion about Reform of Professional Education in Chinese Medicine Specialty under the Professional Certification. Chinese Medicine Modern Distance Education of China. 2016;14(13):8-9, 24.

33. Xu X, Wu X, Wnag J, Davey AK. Pharmacy Education Quality Assurance in China: Moving Towards a National Accreditation System?. Pharmacy Education. 2010;10(2):47-9.

34. Penm J, Li Y, Zhai S, Hu Y, Chaar B, Moles R. The impact of clinical pharmacy services in China on the quality use of medicines: A systematic review in context of China's current healthcare reform. Health Policy Plan. 2014;29(7):849-72. 


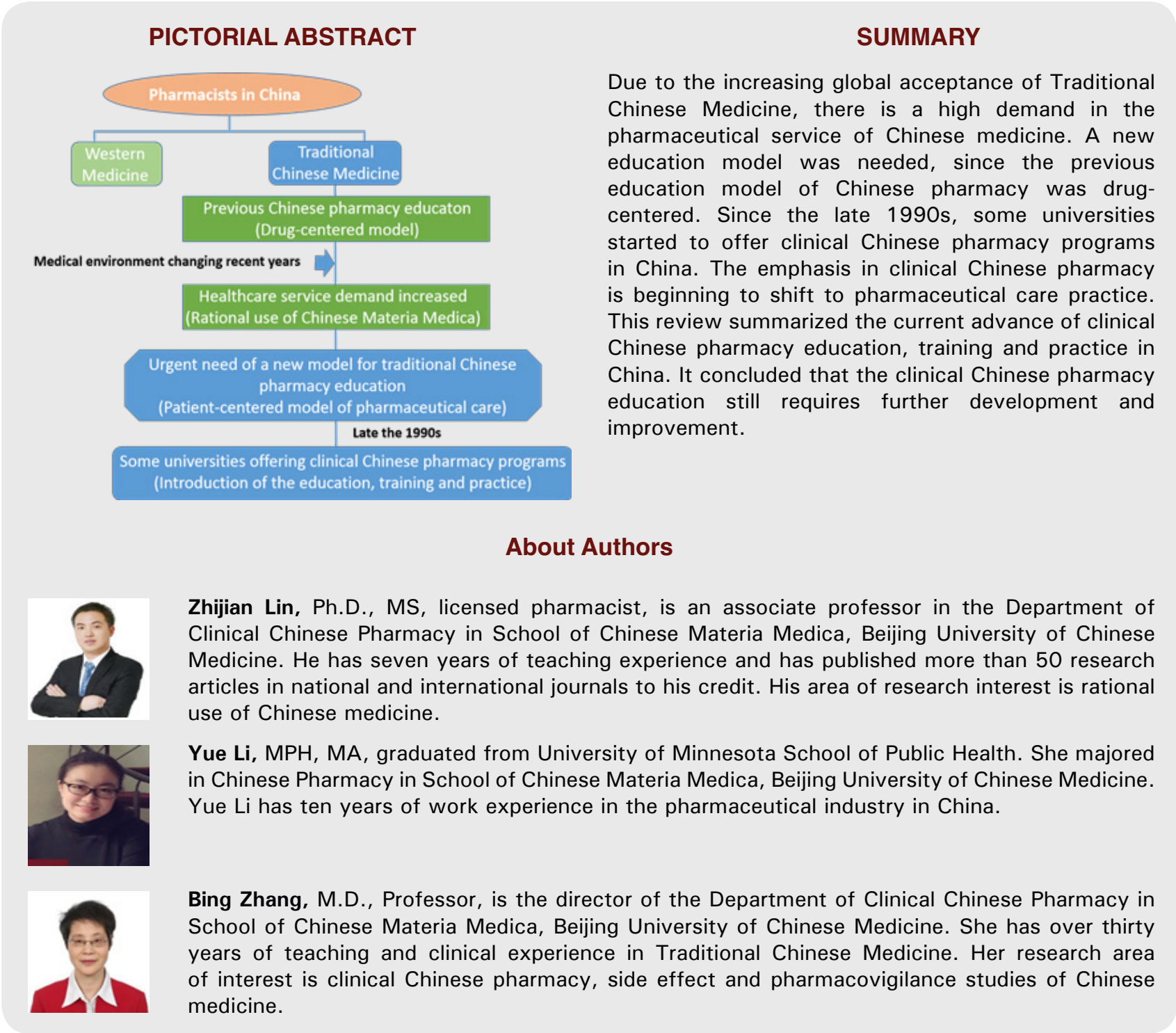

Cite this article: Lin Z, Li Y, Zhang B. A Brief Introduction of Clinical Chinese Pharmacy Education, Training and Practice in China. Indian J of Pharmaceutical Education and Research. 2021;55(1):26-35. 